\title{
Sucul Organizmalarda Çevresel Şartlara Karşı Geliştirilen Oksidatif Stres Mekanizmaları ve Adaptif Yanıtlar
}

\author{
Güllü KAYMAK ${ }^{1}$, Cansu AKBULUT ${ }^{1}$, Harika Eylül ESMER ${ }^{2}$, \\ Figen Esin KAYHAN ${ }^{2}$, Nazan Deniz YÖN ${ }^{1}$ \\ ${ }^{1}$ Sakarya Üniversitesi, Fen Edebiyat Fakültesi, Biyoloji Bölümü, 54187 Esentepe, Sakarya. \\ ${ }^{2}$ Marmara Üniversitesi, Fen Edebiyat Fakültesi, Biyoloji Bölümü, 34722 Göztepe, İstanbul.
}

\begin{abstract}
Özet
Sucul ekosistemlerdeki kirlilik, ciddi ve artan bir problemdir. Endüstriyel, tarımsal ve ticari kimyasalların yüksek oranda sucul çevreye deşarj edilmesi sucul canlılarda çeşitli zararlı etkilere neden olur. Biyolojik sistemlerde oksidatif stres, reaktif oksijen türlerini (ROT) artırarak veya antioksidan savunma sistemlerine hasar vererek oluşur. Balıklardaki oksidatif stresin neden olduğu biyokimyasal ve fizyolojik hasarlar, stresin şiddetine, mekanizmasına ve antioksidan enzim aktivitesine bağlıdır. Bu derlemede, sucul organizmaların çevresel şartlara karşı geliştirdikleri oksidatif stres ve adaptif yanıtların incelendiği çalışmalar ele alınmıştır.
\end{abstract}

Anahtar Kelimeler: Oksidatif Stres, Sucul Organizmalar, Çevre Kirliliği

\section{Oxidative Stress Mechanisms and Adaptive Responses in Aquatic Organisms Against to Environmental Conditions}

\begin{abstract}
Pollution of the aquatic ecosystems is a serious and evergrowing problem. Increasing amount of industrial, agricultural and commercial chemicals discharges into the aquatic environment have led to various harmful effects on the aquatic organisms. Oxidative stress is caused through damaged biological systems via producing Reactive Oxigen Species (ROS) or by impairing antioxidant defense systems. Biochemical and physiological damages caused by oxidative stress in fish depend on antioxidant enzyme activities, stress intensity and its mechanism. This paper reviews the studies on oxidative stress developed by aquatic organisms against environmental conditions and their adaptive responses.
\end{abstract}

Keywords: Oxidative Stress, Aquatic Organisms, Environmental Pollution

\section{Giriş}

Tüm organizmalarda olduğu gibi sucul canlılarda da çevresel şartlar nedeniyle oluşan stres etkileri, oksidatif stres ile ilişkilendirilebilir. Sucul canlılarda oksidatif strese neden olduğu bilinen çevresel şartlar genellikle; sıcaklık, oksijen seviyesi, tuzluluk, mevsimsel ritim değişiklikleri, geçiş metal iyonları, pestisitler ve petrol türevleri olarak sınıflandırılabilir. $\mathrm{Bu}$ derleme çalışmasında, sucul organizmaların çevresel şartlara karşı geliştirdikleri oksidatif stres ve adaptif yanıtların irdelenmesi amaçlanmıştır.

\subsection{Sıcaklık ve Oksijen Seviyesi}

Sıcaklık ve çözünmüş oksijen seviyesi sucul canlıların dağılımında önemli parametrelerdir. Sıcaklık, tüm canlı organizmaları etkiler, ancak ektotermik hayvanlar için daha kritiktir. 
Artan ya da azalan çevresel sicaklığın oksidatif stresi tetiklemesi sucul organizmalarda farklı mekanizmalarda gerçekleşir. Sıcaklık artışı ve azalması, sucul canlılarda tüm metabolik süreçleri etkiler. Örneğin; yüksek sıcaklık, oksijen tüketimini artırır.

Böylece, Reaktif Oksijen Türlerinin (ROT) üretimi de artar ve organizmalarda oksidatif strese karşı gelişen bazı savunma amaçlı adaptif yanıtlar görülür [1]. Çevresel sıcaklıktaki artışların, kurbağalarda [2], balıklarda [3-8], ve diğer sucul canlılarda [9,10] oksidatif stres oluşumuna yol açtığı bazı araştırmalarda rapor edilmiştir. Sıcaklıktaki azalma ise oluşan oksidatif stres riskini düşürebilir. Ancak yine de bazı şartlarda çevresel sıcaklığın azalması balıklarda ve Kaya Midyesi'nde (Balanus balanoides) oksidatif strese neden olabilir [11,12].

Bütün çok hücreli hayvanlar için oksijen yaşamsal bir maddedir. Oksijen tüketimi, balık metabolizması için de önemli bir kriterdir. Sucul ekosistemlerde biyolojik aktivitenin tipi ve miktarı ortamda bulunan çözünmüş oksijen seviyesine bağlıdır. Kirlenen sulardaki çözünmüş oksijen, hazır oksitlenebilen maddeler (metaller, pestisitler vs.) ya da biyolojik faaliyetler nedeniyle hızla azalır. Hipoksia (oksijen azlığı) balıklar için aslında kritik seviyede olsa bile üstesinden gelinebilecek bir durumdur. Hipoksia, akuatik sistemlerde doğal veya insan kaynaklı olabilir. Doğal yollar; ötrofikasyon, su hareketleri ve mevsimsel değişimlerle ortaya çıkar. İnsan kaynaklı hipoksia ise, kimyasal ve biyolojik atıkların ortamda artması sonucu görülür. Oksijen derişimindeki azalma ise, canlılardaki serbest radikallerin oluşumunu azaltabilir. Bu birçok durumda doğru olabilir. Ancak, çevresel oksijen derişimlerindeki azalmalar da oksidatif strese neden olabilir. Örneğin; Japon balığında (Carassius auratus), düşük oksijen maruziyeti karaciğerde "oksidatif strese hazırlığın" bir göstergesi olarak iddia edilen süperoksit dismutaz (SOD) ve katalaz (CAT) aktivitesini artırmıştır [13,14]. Bu hipoteze göre, organizmaların evriminde normal ve aşırı çevresel koşullar arasında geçişlere adaptasyon durumu söz konusudur, yani herhangi bir koşula aşırı maruziyet hayatta kalmaya yardım eden adaptif cevapları harekete geçirir. Örneğin, organizmalar düşük oksijene maruz kaldıkları zaman, uygun koşulların geri dönmesi durumunda oluşabilecek oksidatif stresi engellemek için antioksidan yanıtları arttırırlar. Bu durum "oksijen paradoksu" olarak bilinir. Örneğin bir çalışmada; hipoksinin Cyprinus carpio karaciğerinde SOD ve CAT aktivitesini arttırdığı bildirilmiş ve "oksidatif strese hazırlık" görüşü çerçevesinde adaptif bir yanıt geliştirdiği rapor edilmiştir [15]. Örneğin; Percottus glenii (Çin Uykucu balığı) türünde de hipoksik ortam şartlarının oksidatif stres oluşumuna neden olduğu belirtilmiştir [16]. Yapılan diğer bir çalışmada, Medaka balığında (Oryzias latipes) hipoksiye bağlı glutatyon-Stransferaz seviyesinin arttığı ve buna bağlı oksidatif stres oluşumu bildirilmiştir [17]. Corbicula fluminea (Asya tatlısu midyesi)'nde, ortamdaki oksijen azlığının CAT ve glutatyon peroksidaz (GSH) enzim aktivitesini arttırdığı gözlenmiştir [18].

Oksijen azlığına bağlı oksidatif stres mekanizması henüz tam olarak belirlenememiştir. Ancak bir kaç olası mekanizma öngörülebilir. İlk olarak, hipoksik koşullar altındaki elektron transfer zincirinin taşıyıcıları sınırlı oksijen durumuna bağlı olarak daha da azalır. Bu nedenle daha fazla elektron zincirden kaçar ve oksijenle birleşir. İkinci mekanizma ise, ksantin redüktaz / ksantin oksidaz sistemi ile ilişkilendirilebilir. Hipoksik şartlarda ilk enzim ksantin redüktaz, sınırlı proteoliz veya oksidasyon vasıtasıyla ikinciye dönüşebilir ve ROT üretimini hızlandırabilir [19]. Sucul ortamda yüksek oksijen miktarına (Hiperoksiya) maruz kalmanın da farklı balık türlerinde, örneğin; Japon balığ1 Carassius auratus [20], Atlantik Salmonu (Salmo salar) [21], ve Senegal Dil balığında (Solea senegalensis) [22] oksidatif strese neden olduğu bildirilmiştir. Antarktik Deniz tarağı (Adamussium colbecki), Akdeniz Deniz tarağ 1 (Pecten jacobaeus) [23] ve Deniz Anemonu (Anthopleura elegantissima) [24] ile yap1lan çalışmalarda da benzer sonuçlar elde edilmiştir. Bundan dolayı, çevresel oksijendeki artışın sucul canlılarda oksidatif strese neden olduğu söylenebilir. Artan çözünmüş oksijen seviyeleri ROT üretimini arttırmaktadır. Bu durum, elektron transfer zincirinden kaçan elektronların 
moleküler oksijen ile birleşmesi olarak açıklanabilir. Ancak, organizmalar yüksek çevresel oksijen seviyelerinin olumsuz sonuçlarıyla da başa çıkmak için özel adaptif mekanizmalar geliştirmiştir. Davranış düzeyinde bunlar, oksijen bakımından oldukça zengin alanlardan kaçınmak olabilir, organizma düzeyinde ise, çevresel oksijeni absorbsiyon yeteneğini azaltabilir. Anoksia (oksijen yokluğu) durumunda ise dokular fonksiyonlarını yitirir ve ölürler [25]. Dokular yeterli miktarda oksijen alamazlarsa, hücresel enerji depoları boşalır, toksik metabolitler birikmeye başlar ve serbest radikal üretimin artmasıyla hücreler fonksiyonlarını yitirirler.

Oksijen suda UV'ce zengin güneş 1şınlarının etkisiyle ozon formunda da bulunabilir. Ozon, çok az olarak hava akımı ile alt katmanlara iner, deniz taban seviyesinde çok düşük miktarlarda bulunur [26]. Bu durumda ozon yüksek derişimde olmasa bile, sucul organizmalarda oksidatif stres oluşturmaya yetebilir. Sucul canlılar su arıtma istasyonlarında da ozona maruz kalabilir. Örneğin bir çalışmada; ozona maruz kalan Gökkuşağı alabalığ1 (Oncorhynchus mykiss) eritrositlerinde hemoliz, methemoglobin oluşumu ve eritrosit membranında lipit peroksidasyonu gözlendiği rapor edilmiştir [27]. Ozon ile inkübasyon eritrosit hasarında önemli bir rolü olan $\mathrm{H}_{2} \mathrm{O}_{2}$ üretimini arttırmıştır. Araştırıcılar ozon ve türevlerinin hücreye dışardan direkt saldırdığını ancak, hücre zarından geçebilen ozonun hücre içi hemoglobinler tarafından ROT üretimini uyarmış olabileceği belirtmişlerdir [28].

\subsection{Tuzluluk}

Sucul organizmalarda, tuzluluk değişimi elektrolit dengesinde bozulma, enerji metabolizmasının uyarılması, plazmada strese bağlı hormonların artması gibi çeşitli fizyolojik adaptif yanitlara neden olur. Tuzluluk değişikliğinin neden olduğu stres, oksidatif hasara yol açan yüksek ROT üretimi ile bağlantılıdır [29]. Örneğin, Litopenaeus vannamei (Decapoda, Penaeidae) türü kabuklularda (karideslerde) 24 saatlik akut tuz değişikliğinde SOD, CAT, GSH ve Na+/K+-ATPaz aktivitelerinde değişiklik gözlenmiştir. E vitamininin koruyucu etkisinde devam edilen deney gruplarından orta doz uygulanan karideslerde akut tuzluluk değişimlerine dayanıklılık artarken, yüksek doz E vitamini uygulanan gruplarda herhangi bir etki gözlenmemiştir. Bu sonuçlar, tuzluluk değişikliklerinin oksidatif strese yol açacak kadar toksik olabileceğini ve E vitamininin sadece bazı durumlarda toksik etkiyi azaltabildiğini gösteren bir örnektir [29].

Mersin balıklarının (Acipenser naccarii) tatlı sudan, deniz suyuna kademeli geçişlerinde kanda, karaciğerde ve kalpte CAT, GSH, SOD aktiviteleri ve lipid peroksidasyon (MDA) miktarları ölçülmüştür. Balıkların, 20 gün sonra \%o 35 tuzlulukta, plazma osmolaritesi, eritrosit miktarı ve kas suyu içerikleri açısından yeni ortama fizyolojik adaptasyon sağladıkları görülmüştür. Ancak kanda kortizol değerleri, antioksidan enzim aktiviteleri, lipit peroksidasyonu ve hepatik proteinler başlangıç değerlerine geri dönmemesi osmoregülasyon sürecinin balıklarda önemli fizyolojik değişikliklere neden olduğunu göstermiştir [30]. Artan çevresel tuzluluk şartlarında antioksidan savunma yeteneğinin artması, deniz suyuna geçişte serbest radikal sürecinin bozulması ve antioksidanların adaptasyondaki etkin rolleri ile açıklanabilir. Çevresel tuzluluğun sucul canlılarda serbest radikal süreçlerinde değişikliğe neden olduğu açıkça gösterilmektedir [31].

\subsection{Geçiş metalleri}

Metal iyonlarının oksidatif strese neden oldukları uzun zamandır bilinmektedir. Metal iyonları sucul ortama tarımsal ve endüstriyel faaliyetler, yağmur ve yüzey suları ile taşınarak ve atık sular yoluyla olmaktadır [32,33]. Geçiş metalleri, ROT üretimini iki farklı mekanizma ile arttırabilirler. İlk olarak metal ilişkili proseslere etki etmesi, ikincisi ise değişebilen değerlikli iyonlar tarafından serbest radikal oluşturmasıdır. Aslında ikinci mekanizma birincisine engel olabilir, ancak genellikle değişebilen değerlikli iyonların etkisi daha 
baskındır. Sucul canlılarda geçiş metallerinin neden olduğu oksidatif stresle ilgili literatür bilgisi oldukça fazladır. Değerlik durumunu değiştirme yeteneği bu iyonların en önemli özellikleridir [34]. Burada yalnızca organizmalarda fizyolojik ve biyokimyasal özellikleri açısından önemli olan demir, bakır, cıva ve arseniğe değineceğiz.

\subsubsection{Demir}

Ökaryotlarda demir (Fe) metabolizması oldukça iyi irdelenmiştir. Demir, tüm organizmalar için yaşamsal bir elementtir. Organizmalarda demirin hem eksikliği hem de fazlası bazı tehlikeli sonuçlar doğurabilir. Sucul canlılarda demir metabolizması ve fonksiyonları diğer organizmalara benzer şekildedir. Örneğin, balıklar demiri solungaç epitellerinden geçen sularla ve besinler ile alabilirler [35,36]. Demirin yaşamsal süreçte temel unsur olduğu bilinmektedir. Ancak, redoks döngüsü geçirdiği için, serbest radikal süreçlerin oluşumunda da rol oynar. Fakat sucul canlılar için bu elementin serbest radikal süreci ile ilgili bilgiler halen sınırlıdır. Yapılan bir çalışmada, Afrika Kedi balığı (Clarias gariepinus) beş hafta boyunca normal ve demirce zengin besinlerle beslenmiştir. Subletal dozlarda olsa bile toksik olan yüksek demirli besin tüketimi balıklarda büyümeyi yavaşlatabilir. Aynı zamanda serbest radikallerin lipid peroksidasyonu ürünü olan malondialdehit (MDA) konsantrasyonun kalp ve karaciğerde arttığı ve yağda çözünen antioksidan $\alpha$-tokoferolün (E vitamini) karaciğerde önemli ölçüde azaldığı gözlenmiştir. MDA ve $\alpha$-tokoferol miktarındaki değişiklikler yüksek demir içeriğine sahip besinlerin neden olduğu oksidatif stresi işaret etmektedir [37].

Başka bir çalışmada Japon balığının (Carassius auratus) karaciğer ve böbreklerinde suda bulunan demirin serbest radikal sürecine etkileri akvaryum ortamında araştırılmıştır. Uygulama sonrasında protein karbonil grupları ve proteinlerin oksidatif modifikasyon belirteç seviyeleri artmış, fakat lipit peroksitlerin konsantrasyonu azalmıştır. Aynı zamanda TBARS (Tiyobarbiturik asit reaktifleri) konsantrasyonları $500 \mu \mathrm{M}$ demir sülfat uygulanan balıklarda karaciğer ve böbrekte artmıştır. Belirlenen değişiklikler Japon balığı dokularında oksidatif stresin göstergesidir Lipid peroksidasyon ürünleri ve karaciğerdeki katalaz ile böbrekteki glutatyon redüktaz aktiviteleri arasında kuvvetli pozitif ilişki, bu ürünlerin enzimleri yeniden düzenlemeye yönlendirdiğini gösterir [38]. Yapılan bir çalışmada Kara Midye'lerin (Mytilus galloprovincialis), demir iyonlarına maruz bırakılması sonucunda hidroksil radikal üretiminin arttığ bildirilmiştir [39].

\subsubsection{Bakır}

Sucul hayvanlarda, bakır homeostazisi pek çok faktöre bağlıdır ve son derece düzenli süreçlerdir [40,41]. Yapılan bir çalışmada, 67 gün boyunca yüksek bakır içerikli diyetle beslenen Mavi Kefal Balığı'nın (Chelon labrosus), hepatik $\alpha$-tokoferol konsantrasyonu yarı yarıya azalırken, MDA seviyeleri oldukça fazla oranda artmıştır. Bakırın diyetle yüksek alınımı, balıklarda oksidatif stresin neden olduğu sonuçlara yol açmıştır [42]. Başka bir araştırmada, Çipura'ya (Sparus aurata) $\mathrm{CuCl}_{2}$ enjeksiyonu sonucunda tiyobarbitürik reaktif maddeler, SOD enzim aktivitesi ve protein seviyeleri artmıştır [43]. Afrika Kedi balığının (Clarias gariepinus) yüksek dozda bakıra maruziyeti sonucunda, bağırsak, karaciğer ve solungaçlarda bakır derişimini yükseltmiştir. Aynı zamanda solungaç ve bağırsakta TBARS konsantrasyonu önemli derecede artmış ve bağırsakta total glutatyon içeriğinin iki katına çıktığı rapor edilmiştir [44].

Hansen ve arkadaşları, Kahverengi Alabalık (Salmo trutta) dokularında bazı antioksidan enzimlerin mRNA'nın kararlı durum konsantrasyonu ve faaliyetleri üzerine su kirliliğinin etkilerini araştırmışlardır. Çalışmadan çıkan sonuçlara göre, metal iyonlarına özelliklede bakıra maruz kalan balıklarda birincil (SOD, CAT, GSH) ve ikincil (Glutatyon redüktaz (GSSG), Metallotiyonein (MT) enzim aktivitelerinin arttığ ve protein seviyelerinin 
yükseldiği görülmüştür [45,46]. Farklı dozlarda bakır çözeltileri uygulanmış Gökkuşağı Alabalığı'nın (Oncorhynchus mykiss), solungaç hücrelerinde doza bağımlı yüksek sitotoksisite ve oksidatif stres belirtileri gözlenmiştir [47]. Diğer bir araştırmada, farklı dozlarda bakır maruziyetinde Zebra balıklarında CAT aktivitesi değişmezken, protein karbonil konsantrasyonu artmıştır [48]. Tatlı su piresinde (Daphnia magna) bakır iyonlarına maruziyet CAT, glutatyon peroksidaz (GPx), glutatyon-S-transferaz (GST), SOD aktivitesini, TBARS ve lipofuksin seviyesini artırmıştır [49]. Mavi Yengeç (Callinectes sapidus) ile yapılan bir çalışmada, bakır konsantrasyonlarının hücre içi GSH, okside protein seviyelerini ve CAT aktivitesini etkilemediği rapor edilmiştir [50].

\subsubsection{Civa}

Son zamanlarda, balıklarda serbest radikal sürecine civanın etkisini araştıran birçok çalışma yapılmıştır. Civa, toprak ve sudaki mikroorganizmalar tarafından inorganik civanın metilasyonu sonucu oluşan metilciva halinde bulunabilir. Organik ya da inorganik civanın biyolojik etkisi, sülfidril içeren maddeler ile etkileşimine bağlıdır [51]. Civa elementi için, glutatyon yüksek afiniteye sahip olduğundan, ilk olarak hücre içi glutatyon havuzu tükenir ve dolaylı ya da dolaysız olarak oksidatif strese sebep olur [52].

Diğer canlılar gibi balıklarda, bünyelerinde yüksek civa konsantrasyonlarını akümüle edebilirler [53]. Atlantik Salmonu (Salmo salar) ile yapılan bir çalışmada, balıklar dört ay süresince civakloride maruz bırakılmıştır. Metal civa özellikle beyinde birikim göstermiş ancak ölüme veya gelişimde görülebilir bir azalmaya sebep olmamıştır. Ama büyük oranda lipid peroksidasyonunu arttırmış buna karşın SOD ve glutatyon peroksidaz aktivitesini azaltmıştır. Diğer organlarla kıyaslandığında beyin civaya en dayanıksız organdır. $\mathrm{Bu}$ nedenle, düşük konsantrasyonda diyetle alınan civa, beyinde antioksidan enzim SOD'ın indüklenmesiyle oluşan koruyucu redoks savunmaya sebep olmuştur [54]. Bir çalışmada, civa maruziyetinin Altınbaş Kefal'de (Liza aurata) antioksidan enzim aktivitesini azalttığ bildirilmiştir [55]. Sicak iklim tatlı su balığı olan Brycon amazonicus'un civa klorürün subletal dozlarına 96 saat süreyle maruziyeti sonucunda SOD, CAT, GPx, GST ve GSSG-R aktivitelerinin arttığı rapor edilmiştir. Civa, balığın karaciğer ve solungaçlarında indirgenmiş glutatyon seviyesini artırırken, beyaz kas hücrelerinde indirgenmiş glutatyon seviyesini azaltmıştır. $\mathrm{Bu}$ bulgulara ek olarak, diğer bazı dokulardaki harabiyet sonucunda lipid peroksidasyon ve protein karbonil içeriğinin yükseldiği belirtilmiştir [56]. Civa maruziyetinin sebep olduğu oksidatif stres, bu metalin balıklardaki toksisitesinin en önemli göstergesidir.

\subsubsection{Arsenik}

Arsenik, organik ve inorganik bileşikler halinde doğada serbest halde bulunabilir. İnorganik arsenik; arsenit $\left(\mathrm{As}^{+3}\right)$ ve arsenat $\left(\mathrm{As}^{+5}\right)$ formlarında görülür. İnorganik arsenikler metilli (monometilarsenik asit, MMA) ya da dimetilli (dimetil arsenik asit, DMA) olabilir. Fizyolojik koşullar altında arsenitin $\left(\mathrm{As}^{+3}\right)$, arsenata $\left(\mathrm{As}^{+5}\right)$ oksidasyonu sonucu, $\mathrm{H}_{2} \mathrm{O}_{2}$ oluşumu gözlenebilir [57]. Bu nedenle, arsenik bileşikleri, hücre bileşenlerinden özellikle lipidleri, DNA ve proteinleri okside ederek ROT üretimini artırırlar.

Schlenk ve arkadaşları (1997), Kanal Kedi balığı'nın (Ictalurus punctatus) karaciğer dokusunda arsenit, arsenat ve bir herbisit olan monosodyum metal arsonatın, karaciğer metalloprotein ekspresyonuna ve lipid peroksidasyonuna etkilerini araştırmışlardır. Çalışma sonunda metallotiyonein seviyesinin doza bağlı olarak arttı̆̆ını, karaciğer lipid peroksidasyonu (TBARS) ve GSH konsantrasyonunun ise hiç bir arsenik uygulamasında değişmediğini belirlemişlerdir [58]. Benzer şekilde, Japon balığının karaciğeri üzerinde, farklı dozlarda arsenit uygulamasının oksidatif stres belirteçleri ve antioksidan savunmaya etkisinin araştırıldığı başka bir çalışmada, uygulamanın 1-4 günlerinde TBARS ve protein karbonil konsantrasyonlarının etkilenmediği, ancak okside glutatyon, total glutatyon seviyesi ve lipid 
peroksitlerin artması sonucunda oksidatif stresin geliştiğini göstermiştir. SOD, CAT ve GPx gibi temel antioksidan enzimlerin aktiviteleri, antioksidan cevabın gelişmesiyle artmıştır [8]. Yukarıda adı geçen balık türlerinin doku ve organları üzerine çeşitli arsenik bileşiklerinin etkilerini dikkate aldığımızda, bu elementin hücre metabolizmasına girmesi sonucu serbest radikal üretiminin arttığını söylemek mümkündür. Bu tip bileşikler membranlarda dahil olmak üzere hemen hemen tüm hücresel bileşenleri değiştirebilir. Birçok faktörün bir arada rol oynadığ bu durum, zincir nekroz ya da apoptoz nedeniyle hücre ölümleriyle sona erer.

\subsection{Pestisitler}

Pestisitler istenmeyen zararlı bitki ve hayvanları öldürmek amacıyla kullanılan fiziksel, kimyasal veya biyolojik ajanlardır. Çoğu tarım ilaçları çevre ve insanlar için yeni sentetik ajanlardır ve bu nedenle biyolojik sistemler üzerindeki etkilerini tahmin etmek kolay değildir. Bunun gibi toksik maddeler çeşitli mekanizmalar ile canlılarda oksidatif strese neden olabilirler. Örneğin; toksik maddeler hücresel bileşenlerin elektron alma/verme gibi redoks döngülerine (geri dönüşümlü oksidasyon yoluyla) girerek ROT seviyesini arttırabilirler, hücre metabolizmasında glutatyon gibi indirgeyicilerin rezervlerini tüketebilir ve sonuçta antioksidan potansiyelini azaltabilirler, antioksidan ve azalmış antioksidan potansiyeline yol açan enzimleri aktive edebilirler, enerji sağlayan süreçlere müdahale ederek detoksifikasyon ve metabolizma için gerekli kaynakları azaltabilirler ve temel yaşamsal süreçlerdeki değişimler (transkripsiyon ve translasyon gibi) dolaylı yoldan ROT düzeyini arttırabilirler [59]. Aşağıda tarımsal mücadelede sıklıkla kullanılan ve sucul ortamlara kolayca karışabilen bazı pestisit gruplarının, sucul canlılarda nasıl oksidatif strese yol açtı̆̆ını gösteren bazı örnekleri irdeleyeceğiz.

\subsection{1. İnsektisitler}

$\mathrm{Bu}$ başlıkta sadece insektisitleri değil aynı zamanda bazı akarisitleride ele alacağız. Birçok insektisit, böcekleri tarım ürünler, ev ve depolanan ürünlerden uzak tutmada ve evcil ve çiftlik hayvanlarında dış parazit enfeksiyonlarında sıkça kullanılan Organofosfat (OP) bileşikleridir. Etki mekanizmaları, sinirlerde sinyal iletimi sonlanmasından sorumlu olan asetil kolin esteraz (AChE) enziminin inhibisyonu ile ilgilidir. Bu, OP'ların omurgalı ve omurgasız canlılarda ilk etkisidir. Merkez ve periferal sinir sinapslarında nörotransmitter asetilkolinin (ACh) hidrolizini durdururlar ve aşırı ACh birikimine ve ACh reseptörlerinin aktivasyonuna yol açarlar [19]. Organofosfatların toksik etkisinin, büyük ölçüde sinaptik yarıkta ACh birikimi sonucunda kolinerjik sistemin hiperaktivitesine bağlı olduğu düşünülmektedir. Sinir ve endokrin sinyallerdeki kesintiler, hücre içinde $\mathrm{Ca}^{+2}$ değişimine ve böylece oksidatif strese neden olan nitrik oksit sentaz gibi proteolitik enzimlerin aktivasyonuna ve serbest radikallerin üretilmesinde artışa yol açar. Karaciğerde organofosfatların metabolizması glutatyon tüketimine bağlıdır ve bu da oksidatif stres oluşturabilir. Organofosfat uygulanan balıklarda gelişen oksidatif stres ile ilgili birçok çalışma bulunmaktadır. Örneğin, diklorvosun Avrupa Yılan balığında (Anguilla anguilla) [60], triklorfonun Nil Tilapyasında [61], Folisuper 600BR (metil paratiyon)'nin Brycon cephalus'ta [62], fentiyonun Oreochromis niloticus'ta [63] ve malatiyonun, Çipura'da [64] oksidatif stresi artırdığı belirlenmiştir. Lindan ve DDT'nin de dahil olduğu başka bir insektisit grubu olan klorlu hidrokarbonlar, Cyprinus carpio'da deri tümor hücreleri ve Hoplias malabaricus hepatositlerinde oksidatif stresi arttırmışlardır [65,66]. Fenpiroksimat meyve bahçelerinde akarlara karşı kullanılan bir akarisittir. Lepistes balıklarına (Poecilia reticulata), fenpiroksimatın farklı subletal dozlarının uygulandığı bir çalışmada balıkların karaciğer dokularında toplam antioksidan kapasite ve toplam oksidatif durum gibi biyokimyasal parametreler incelenmiştir. Çalışma sonunda antioksidan aktivitede bir değişikliğin izlenmediği ancak 25 ve 50 mikrogram FP uygulanan gruplarda oksidatif stres gözlendiği rapor edilmiştir [67]. 


\subsubsection{Herbisitler}

$\mathrm{Bu}$ başlık altında iki herbisit grubu incelenecektir: İlk olarak; Paraquat (N,N'-dimetil4,4'-bipiridinyum diklorid) gibi serbest radikal üretimini artıran, redoks döngüsüne giren ve sürekli ROT üretiminden doğrudan sorumlu olanlar ve aminotriazol ve ditiyokarbamat gibi antioksidan enzimleri inhibe edenlerdir. Paraquat'in Y1lanbaş (Channa punctata) [68], Zebra balığı (Danio rerio) [69] ve Gökkuşağı alabalığı'nda [70] oksidatif stresi artırdığı rapor edilmiştir. Benzer şekilde, diquat, sazan karaciğer hücrelerinde [71] ve gökkuşağı alabalığının solungaç dokularında [72] ROT üretimini uyarmıştır.

SOD ve CAT gibi antioksidan enzimleri inhibe eden ikinci grup herbisitler ise çeşitli bileşik gruplarından oluşur. Hai ve ark. (1997a) dietilditiyokarbamat (DDC) sazan dokularında pro/antioksidan sistemi modifiye etmesine rağmen, aynı zamanda kendi yapısında tiyol gruplarının varlığı nedeniyle antioksidan olarak görev yaptığını belirlemişlerdir [73]. Yaşlı balık dokularında DDC'nin oksidatif stresi arttırdığ 1 belirtilmiştir [74]. Diğer bir araştırmada tiyokarbamatlı herbisitlerden olan molinatın Avrupa Yılan balığı'nda (Anguilla anguilla) oksidatif stresi arttırdı̆̆ 1 belirtilmiştir [75]. Molinat, glutatyon ile konjugasyonu takiben, endoplazmik retikulum oksijenaz sistemi tarafindan sülfoksidasyon yolu ile detoksifiye olduğundan, maruziyeti sonucu canlılarda oksidatif stresi indükleyebilir. Benzer şekilde, aminotriazol (3-amino-1,2,4-triazol, AMT) heterosiklik organik bileşikte ve seçici olmayan, yaygın kullanılan bir herbisittir. İmidazolgliserol-fosfat dehidratazın yarışmalı inhibitörüdür ve aynı zamanda katalazın aktif merkezindeki demir atomuna bağlanarak katalazı inhibe eder. Aminotriazol maruziyetinin, Gökkuşağı alabalığında ve Japon balığında oksidatif stresi arttırdığ 1 rapor edilmiştir [76-78]. Herbisitlerin çoğu oksidatif stresi arttırarak kendi biyolojik aktivitelerini ortaya koyarlar. Örneğin, glifosat (N-fosforometilglisin), 5enolpürivil-3-fosfat sentaz enzimini (EPSPS) inhibe ederek, aromatik aminoasitlerin sentezini etkileyen, yabani bitki büyümesini engelleyen ve seçici olmayan bir herbisittir. Bu enzim bitkilerde fenilalanin, tirozin ve triptofan biyosentezinde ara ürün olan korismat'ın biyosentezinden de sorumludur. Yapılan bir araştırmada, glifosat kökenli bir herbisit olan Roundup, Japon balığında oldukça az da olsa oksidatif stresi arttırmıştır [79]. Diğer bazı balık türleri olan Piava (Leporinus obtusidens) ve Gümüş Kedi balığ (Rhamdia quelen) ile yapılan çalışmalarda da Roundup'un oksidatif stresi indüklediği gözlenmiştir [80,81].

\subsubsection{Fungusitler}

En etkili fungisitler, formülasyonlarında bakır bulunduran bileşiklerdir. Örneğin, hekzaklorobenzen (HCB) ya da perklorobenzenin, Pullu Sazan balığının (Cyprinus carpio) beyin ve karaciğerinde oksidatif stresi artırdığı belirlenmiştir. Ülkemizde İmazalil (IMA) fungusiti özellikle meyve bahçelerinde yaygın olarak kullanılmaktadır. Zebra balığı embriyolarına farklı dozlarda imazalil uygulanması sonucunda kromozomlarda morfolojik değişiklikler gözlenmiştir. İmazalilin hem ekosistem hem de insanlar için potansiyel bir risk faktörü olduğu rapor edilmiştir [82]. HCB'lerin kullanımı Stockholm sözleşmesinde küresel olarak yasaklanmış olmasına rağmen, hala birçok endüstriyel işlemlerde yan ürün olarak çevreye salınan en yaygın kalıcı organik kirleticilerden biridir. HCB'lerin ROS üretimini iki yolla artırdığ1 düşünülmektedir. Birincisi, yağda çözünebilen bir madde olan HCB, sitokromlara bağlanabilir ve kolayca metabolize edilmesi engellenir, böylece mono-oksijenaz aktivitesinden elektron transfer zincirini ayırır ve dolayısıyla reaktif türlerin üretimini teşvik eder. İkincisi, HCB'nin önemli metabolitlerinden biri olan pentaklorofenolün metabolizma için zaten güçlü bir ROS kaynağı olmasıdır [83]. Geniş spektrumlu bir fungusit olan Prokloraz (N-propil-N-(2-(2,4,6-triklorofenoksietil), özellikle sitokrom P450 enzim aktivitelerini etkileyerek sucul organizmalar üzerinde olumsuz etkiler meydana getirebilir. Dikence balığı (Gasterosteus aculeatus) ile yapılan bir çalışmada, proklorazın, glutatyon 
havuzunu tükettiği ve antioksidan enzimlerde geçici bir artışı indüklediği rapor edilmiştir. Araştırmacılara göre, heterosiklik halkanın hidroksilasyonu sonucu oluşan ürünler oksidatif stres meydana getirmiş olmaktadır [84].

\subsection{Petrol ve türevleri}

Tüketilen petrolün çok daha fazlası petrol türevleri olarak endüstride kullanılmaktadır. Petrol türevleri içerisinde ana kirleticiler polisiklikaromatik hidrokarbonlar (PAH), alkilfenoller ve hidrokarbonlardır. PAH'lara maruziyet sonucunda sucul organizmalarda oksidatif stres belirlenmesi pek çok araştırmacı tarafindan rapor edilmiştir [85-88]. Petrol türevi bu maddelerin toksisitelerinin en önemli unsurlarından biri de canlılarda meydana gelen oksidatif strestir. PAH öncelikle hidroksilasyon yolu ile metabolize olur ve böylece sitokrom P450 sisteminde (özellikle CYP1A) enzimler tarafindan detoksifiye edilirler [89]. Bu metabolizma redoks döngüsüne giren bileşiklerin oluşmasına yol açar. ROS üretiminde potansiyel iki mekanizma söz konusu olabilir. Birincisi, GSH tüketimi ile sonuçlanan glutatyon ile metabolizma ürünlerinin konjugasyonu ve savunma potansiyelini azaltarak oksidatif strese yol açmaktadır. İkincisi de sadece redoks döngülerine girebilecek metabolitler ile ilişkili olabilir. Atlantik Morina balığı (Gadus morhua) ile yapılan bir araştırmada, alkil fenollere maruz kalmanın muhtemel oksidatif stres sonucu glutatyon reduktaz aktivitesini ve toplam glutatyon seviyesini arttırdığ 1 gösterilmiştir [90,91]. Nonifenol'ün, Atlantik Morina balığında, Büyük ağızlı Tatlısu Levreği'nde (Micropterus salmoides) ve gökkuşağı alabalığında (O. mykiss) GSH seviyesini azalttığı bazı çalışmalarda gösterilmiştir [92,93]. İnsanların maruz kaldıkları önemli çevresel kirleticilerden biri de Bisfenol A (BPA)'dır. Genellikle plastik sertleştirme işleminde kullanılan BPA canlılarda endokrin sistemde hasar oluşturur. Akbulut ve ark., (2013) tarafından yapılan bir çalışmada, BPA'nın zebra balıklarının embriyo ve larvalarında primordiyal germ hücreleri üzerine etkileri araştırılmıştır. Endokrin sistem hormonları ve çevresel etkenler primordiyal germ hücrelerinin göçünü etkilemektedir. Düşük dozlardaki BPA'nın bile primordiyal germ hücre sayısını arttırdığı ve bu hücrelerin ektopik bölgelere göç etmesine neden olduğu rapor edilmiştir [94]. Yarı sentetik petrol türevi yağlar olan Poliklorlu Bifenil bileşikleri (PCB) pek çok sanayileşmiş ülkenin çevre ve insan sağlığı açısından üzerinde çalışmalar yaptığ 1 kimyasal bileşikler grubudur. Tüm dünyada PCB'lerin sebep olduğu kirlilik nedeniyle balık türlerinde $10 \mathrm{ppm}$, hayvan vücut yağlarında $300 \mathrm{ppb}$, bitkisel yağlarda $150 \mathrm{ppb}$, hayvan etlerinde 10-30 ppb, tavuk yumurtalarında $30 \mathrm{ppb}$ ve düşük yağ içerikli besinlerde de 5 ppb dolayında PCB kirliliğine rastlandığı bazı araştırmacılar tarafindan rapor edilmiştir [82].

Sonuç olarak organizmaların sahip olduğu en önemli özelliklerden biri hücrelerinde enerji akışının kontrol edilmesidir. Reaktif oksijen türlerinin oluşması sonucunda gelişen oksidatif stres çeşitli mekanizmalar yoluyla biyomoleküllere zarar vermektedir. Sucul organizmalarda antioksidan savunma sistemleri, çevresel şartlara bağlı olarak değişmekte ve adaptif bazı yanıtlar geliştirmektedir. Sucul canlıların doku ve organlarında görülebilen yanıtlar, aslında ekosistemin tümüyle olumsuz etkilendiğinin de bir göstergesidir.

\section{KAYNAKLAR}

[1] Maderia, D., Narciso, L., Cabral, H.N., Vinagre, C., Diniz, M.S. (2013). Influence of temperature in thermal and oxidative stress responses in estuarine fish. Comp. Biochem. Physiol. A. Mol. Integr. Physiol., 166(2): 237-243. DOI: 10.1016/j.cbpa.2013.06.008.

[2] Bagnyukova, T.V., Storey, K.B., Lushchak, V.I. (2003). Induction of oxidative stress in Rana ridibunda during recovery from winter hibernation. J. Therm. Biol., 28: 21-28. DOI: $10.1016 / \mathrm{S} 0306-4565(02) 00031-1$ 
[3] Parihar, M.S., Dubey, A.K. (1995). Lipid peroxidation and ascorbic acid status in respiratory organs of male and female freshwater catfish Heteropneustes fossilis exposed to temperature increase. Comp. Biochem. Physiol., C 112: 309-313.

[4] Heise, K., Puntarulo, S., Nikinmaa, M., Abele, D., Pörtner, H.O. (2006a). Oxidative stress during stressful heat exposure and recovery in the North Sea eelpout Zoarces viviparus L. J. Exp. Biol., 209: 353-363. DOI:10.1242/jeb.01977

[5] Heise, K., Puntarulo, S., Nikinmaa, M., Lucassen, M., Pörtner, H.O., Abele, D. (2006b). Oxidative stress and HIF-1 DNA binding during stressful cold exposure and recovery in the North Sea eelpout (Zoarces viviparus). Comp. Biochem. Physiol., A 143: 494-503. DOI:10.1016/j.cbpa.2006.01.014

[6] Lushchak, V.I., Bagnyukova, T.V. (2006). Effects of different environmental oxygen levels on free radical processes in fish. Comp. Biochem. Physiol., B 144: 283- 289. DOI: 10.1016/j.cbpb.2006.02.014

[7] Bagnyukova, T.V., Danyliv, S.I., Zin'ko, O.S., Lushchak, V.I. (2007a). Heat shock induces oxidative stress in rotan Perccottus glenii tissues. J. Therm. Biol., 32: 255-260. DOI: $10.1016 /$ j.jtherbio.2007.01.014

[8] Bagnyukova, T.V., Luzhna, L.I., Pogribny, I.P., Lushchak, V.I. (2007b). Oxidative stress and antioxidant defenses in goldfish liver in response to short-term exposure to arsenite. Environ. Mol. Mutagen., 48: 658-665. DOI:10.1002/em.20328

[9] Verlecar, X.N., Jena, K.B., Chainy, G.B., 2007. Biochemical markers of oxidative stress in Perna viridis exposed to mercury and temperature. Chem. -Biol. Interact. 167, 219226. DOI: 10.1016/j.cbi.2007.01.018

[10] Bocchetti, R., Lamberti, C.V., Pisanelli, B., Razzetti, E.M., Maggi, C., Catalano, B., Sesta, G., Martuccio, G., Gabellini, M., Regoli, F. (2008). Seasonal variations of exposure biomarkers, oxidative stress responses and cell damage in the clams. Tapes philippinarum, and mussels, Mytilus galloprovincialis, from Adriatic sea. Mar. Environ. Res., 66: 24-26. DOI: 10.1016/j.marenvres.2008.02.013.

[11] Niyogi, S., Biswas, S., Sarker, S., Datta, A.G. (2001). Seasonal variation of antioxidant and biotransformation enzymes in barnacle, Balanus balanoides, and their relation with polyaromatic hydrocarbons. Mar. Environ. Res., 52: 13-26. DOI: 10.1016/S01411136(00)00257-9

[12] Malek, R.L., Sajadi, H., Abraham, J., Grundy, M.A., Gerhard, G.S. (2004). The effects of temperature reduction on gene expression and oxidative stress in skeletal muscle from adult zebrafish. Comp. Biochem. Physiol., C 138: 363-373. DOI: 10.1016/j.cca.2004.08.014

[13] Hermes-Lima, M., Storey, J.M., Storey, K.B. (1998). Antioxidant defenses and metabolic depression. The hypothesis of preparation for oxidative stress in land snails. Comp. Biochem. Physiol., B 120: 437-448. DOI: 10.1016/S0305-0491(98)10053-6

[14] Lushchak, V.I., Lushchak, L.P., Mota, A.A., Hermes-Lima, M. (2001). Oxidative stress and antioxidant defenses in goldfish Carassius auratus during anoxia and reoxygenation. Am. J. Physiol. Regul. Integr. Comp. Physiol., 280: 100-107.

[15] Lushchak, V.I., Bagnyukova, T.V., Lushchak, O.V., Storey, J.M., Storey, K.B. (2005b). Hypoxia and recovery perturb free radical processes and antioxidant potential in common carp (Cyprinus carpio) tissues. Int. J. Biochem. Cell Biol., 37: 1319-1330. DOI:10.1016/j.biocel.2005.01.006

[16] Lushchak, V.I., Bagnyukova, T.V. (2007). Hypoxia induces oxidative stress in tissues of a goby, the rotan Perccottus glenii. Comp. Biochem. Physiol., B 148: 390-397. DOI: 10.1016/j.cbpb.2007.07.007

[17] Oehlers, L.P., Perez, A.N., Walter, R.B. 2007. Detection of hypoxia-related proteins in medaka (Oryzias latipes) brain tissue by difference gel electrophoresis and de novo 
sequencing of 4-sulfophenyl isothiocyanate-derivatized peptides by matrix-assisted laser desorption/ionization time-of-flight mass spectrometry. Comp. Biochem. Physiol., C 145: 120-133. DOI: 10.1016/j.cbpc.2006.06.005

[18] Vidal, M.L., Bassères, A., Narbonne, J.F. (2002). Influence of temperature, pH, oxygenation, water-type and substrate on biomarker responses in the freshwater clam Corbicula fluminea (Müller). Comp. Biochem. Physiol., C 132: 93-104. DOI: 10.1016/S1532-0456(02)00051-0

[19] Tu, H.T., Silvestre, F., De Meulder, B., Thome, JP., Phuong, N.T., Kestemont, P. (2012). Combined effects of deltamethrin, temperature and salinity on oxidative stress biomarkers and acetylcholinesterase activity in the black tiger shrimp (Penaeus monodon). Chemosphere, 86: 83-91.

[20] Lushchak, V.I., Bagnyukova, T.V., Husak, V.V., Luzhna, L.I., Lushchak, O.V., Storey, K.B. (2005a). Hyperoxia results in transient oxidative stress and an adaptive response by antioxidant enzymes in goldfish tissues. Int. J. Biochem. Cell Biol., 37: 1670-1680. DOI: 10.1016/j.biocel.2005.02.024

[21] Olsvik, P.A., Kristensen, T., Waagbø, R., Rosseland, B.O., Tollefsen, K.E., Baeverfjord, G., Berntssen, M.H. (2005). mRNA expression of antioxidant enzymes (SOD, CAT and GSH-Px) and lipid peroxidative stress in liver of Atlantic salmon (Salmo salar) exposed to hyperoxic water during smoltification. Comp. Biochem. Physiol., C 141: 314-323. DOI:10.1016/j.cbpc.2005.07.009

[22] Salas-Leiton, E., Cánovas-Conesa, B., Zerolo, R., López-Barea, J., Cãnavate, J.P., Alhama, J., 2009. Proteomics of juvenile senegal sole (Solea senegalensis) affected by gas bubble disease in hyperoxygenated ponds. Mar. Biotechnol. 11, 473-487. DOI:10.1007/s10126-009-9190-5

[23] Viarengo, A., Canesi, L., Garcia Martinez, P., Peters, L.D., Livingstone, D.R. (1995). Prooxidant processes and antioxidant defence systems in the tissues of the Antarctic scallop (Adamussium colbecki) compared with the Mediterranean scallop (Pecten jacobaeus). Comp. Biochem. Physiol., B 111: 119-126. DOI: 10.1016/03050491(94)00228-M

[24] Dykens, J.A., Shick, J.M., Benoit, C., Buettner, G.R., Winston, G.W. (1992). Oxygen radical production in the sea anemone Anthopleura elegantissima and its endosymbiotic algae. J. Exp. Biol., 168: 219-241.

[25] Keleştemur G. T. (2012). Hipoksik Suların Balıklar Üzerinde Oluşturduğu Fizyolojik Etkiler. Türk Bilimsel Derlemeler Dergisi, 5 (1):87-90.

[26] Güven, C.K., Öztürk, B. Deniz Kirliliği. Temel Kirleticiler ve Analiz Yöntemleri. Türk Deniz Araştırmaları Vakfı. TÜDAV Yayınları. No:21. Beykoz, İstanbul. ISBN 9758825-08-9.

[27] Davidson, J., Good, C., Welsh, C., Summerfelt, S. (2011). The effects of ozone and water exchange rates on water quality and rainbow trout Oncorhynchus mykiss performance in replicated water recirculating systems. Aquac. Eng. 44:3, 80-96. DOI: 10.1016/j.aquaeng.2011.04.001

[28] Hébert, N., Gagné, F., Cejka, P., Bouchard, B., Hausler, R., Cyr, D.G., Blaise, C., Fournier, M. (2008). Effects of ozone, ultraviolet and peracetic acid disinfection of a primary-treated municipal effluent on the immune system of rainbow trout (Oncorhynchus mykiss). Comp. Biochem. Physiol., C 148: 122-127. DOI: 10.1016/j.cbpc.2008.04.007

[29] Liu, Y., Wang, W.N., Wang, A.L., Wang, J.M., Sun, R.Y. (2007). Effects of dietary vitamin E supplementation on antioxidant enzyme activities in Litopenaeus vannamei (Boone, 1931) exposed to acute salinity changes. Aquaculture, 265: 351-358. DOI: 10.1016/j.aquaculture.2007.02.010 
[30] Martínez-Alvarez, R.M., Hidalgo, M.C., Domezain, A., Morales, A.E., García-Gallego, M., Sanz, A. (2002). Physiological changes of sturgeon Acipenser naccarii caused by increasing environmental salinity. J. Exp. Biol., 205: 3699-3706.

[31] Loro, V. L., Jorge, M. B., Silva, K. R., Wood C. M. (2012). Oxidative stress parameters and antioxidant response to sublethal waterborne zinc in a euryhaline teleost Fundulus heteroclitus: protective effects of salinity. Aquat. Toxicol., 110-111:187-93. DOI: 10.1016/j.aquatox.2012.01.012

[32] Banni, M., Hajer, A., Sforzini, S., Oliveri, C., Boussetta, H., Viarengo, A. (2014). Trancriptional expression levels and biochemical markers of oxidative stress in Mytilus galloprovincialis exposed to nickel and heat stress. Comp. Biochem. Physiol., Part C160:23-29. DOI: 10.1016/j.cbp.2013.11.005

[33] Alak G., Atamanalp M., Uçar A., Arslan H., Şensurat T., Parlak V., Kocaman E. M. (2012). Kahverengi Alabalıklarda (Salmo trutta fario) kadmium toksisitesine karş1 humik asit etkisinin hematolojik parametrelerle araştırılması. Ege J Fish Aqua Sci., 29(4): 181-185 . DOI: 10.12714/egejfas.2013.29.4.06

[34] Koutsogiannaki, S., Franzellitti, S., Fabbri, E., Kaloyianni, M. (2014). Oxidative stress parameters induced by exposure to either cadmium or 17ß-estradiol on Mytilus galloprovincialis hemocytes. The role of signaling molecules. Aquat. Toxicol., 146:186195. DOI: 10.1016/j.aquatox.2013.11.005

[35] Aisen, P., Enns, C., Wessling-Resnick, M. (2001). Chemistry and biology of eukaryotic iron metabolism. Int. J. Biochem. Cell Biol., 33: 940-959. DOI: 10.1016/S13572725(01)00063-2

[36] Bury, N.R., Walker, P.A., Glover, C.N. (2003). Nutritive metal uptake in teleost fish. J. Exp. Biol., 206: 11-23. DOI:10.1242/jeb.00068

[37] Baker, R.T.M., Martin, P., Davies, S.J. (1997). Ingestion of sub-lethal levels of iron sulphate by African catfish affects growth and tissue lipid peroxidation. Aquat. Toxicol., 40: 51-61. DOI: 10.1016/S0166-445X(97)00047-7

[38] Bagnyukova, T.V., Chahrak, O.I., Lushchak, V.I. (2006). Coordinated response of goldfish antioxidant defenses to environmental stress. Aquat. Toxicol., 78: 325-331.

[39] Viarengo, A., Burlando, B., Cavaletto, M.,Marchi, B., Ponzano, E., Blasco, J. (1999). Role of metallothionein against oxidative stress in the mussel Mytilus galloprovincialis. Am. J. Physiol., 277: 1612-1619.

[40] Jorge, M. B., Loro, V. L., Bianchini, A., Wood, C. M., Gillis, P. L. (2013). Mortality, bioaccumulation and physiological responses in juvenile freshwater mussels (Lampsilis siliquoidea) chronically exposed to copper. Aquat. Toxicol., 126:137-147. DOI: 10.1016/j.aquatox.2012.10.014

[41] Kamunde, C., Clayton, C., Wood, C.M. (2002). Waterborne vs. dietary copper uptake in rainbow trout and the effects of previous waterborne copper exposure. Am. J. Physiol., 283: 69-78. DOI:10.1152/ajpregu.00016.2002

[42] Baker, R.T.M., Handy, R.D., Davies, S.J., Snook, J.C. (1998). Chronic dietary exposure to copper affects growth, tissue lipid peroxidation, and metal composition of the grey mullet, Chelon labrosus. Mar. Environ. Res., 45: 357-365. DOI: 10.1016/S01411136(98)00098-1

[43] Pedrajas, J.R., Peinado, J., López-Barea, J. (1995). Oxidative stress in fish exposed to model xenobiotics. Oxidatively modified forms of $\mathrm{Cu}, \mathrm{Zn}$-superoxide dismutase as potential biomarkers. Chem. Biol. Interact., 98: 267-282.

[44] Hoyle, I., Shaw, B.J., Handy, R.D. (2007). Dietary copper exposure in the African walking catfish, Clarias gariepinus: transient osmoregulatory disturbances and oxidative stress. Aquat. Toxicol., 83: 62-72. DOI: 10.1016/j.aquatox.2007.03.014 
[45] Hansen, B.H., Rømma, S., Garmo, Ø.A., Olsvik, P.A., Andersen, R.A. (2006a). Antioxidative stress proteins and their gene expression in brown trout (Salmo trutta) from three rivers with different heavy metal levels. Comp. Biochem. Physiol., C 143: 263-274. DOI:10.1016/j.cbpc.2006.02.010

[46] Hansen, B.H., Rømma, S., Søfteland, L.I., Olsvik, P.A., Andersen, R.A. (2006b). Induction and activity of oxidative stress-related proteins during waterborne $\mathrm{Cu}$ exposure in brown trout (Salmo trutta). Chemosphere, 65: 1707-1714. DOI: 10.1016/j.chemosphere.2006.04.088

[47] Bopp, S.K., Abicht, H.K., Knauer, K. (2008). Copper-induced oxidative stress in rainbow trout gill cells. Aquat. Toxicol., 86: 197-204. DOI: 10.1016/j.aquatox.2007.10.014

[48] Craig, P.M., Wood, C.M., McClelland, G.B. (2007). Oxidative stress response and gene expression with acute copper exposure in zebrafish (Danio rerio). Am. J. Physiol., 293: 1882-1892. DOI:10.1152/ajpregu.00383.2007

[49] Barata, C., Varo, I., Navarro, J.C., Arun, S., Porte, C. (2005). Antioxidant enzyme activities and lipid peroxidation in the freshwater cladoceran Daphnia magna exposed to redox cycling compounds. Comp. Biochem. Physiol., C 140: 175-186. DOI: 10.1016/S0166-445X(97)00047-7

[50] Abele, D., Vazoquez-Medina, J. P., Zentano-Savin, T. (2012). Oxidative stress in aquatic ecosystems. Wiley-Blackwell, UK. ISBN 978-1-4443-3548-4

[51] Rooney, J.P.K. (2007). The role of thiols, dithiols, nutritional factors and interacting ligands in the toxicology of mercury. Toxicology, 234, 145-156. DOI: 10.1016/j.tox.2007.02.016

[52] Valko, M., Leibfritz, D., Moncol, J., Cronin, M.T., Mazur, M., Telser, J. (2007). Free radicals and antioxidants in normal physiological functions and human disease. Int. J. Biochem. Cell Biol., 39, 44-84. DOI: 10.1016/j.biocel.2006.07.001

[53] Guallar, E., Sanz-Gallardo, M.I., van't Veer, P., Bode, P., Aro, A., Gomez-Aracena, J., Kark, J.D., Riemersma, R.A., Martin-Moreno, J.M., Kok, F.J. (2002). Heavy metals and myocardial infarction study group. Mercury, fish oils, and the risk of myocardial infarction. N. Engl. J. Med., 347: 1747-1754.

[54] Berntssen, M.H.G., Aatland, A., Handy, R.D. (2003). Chronic dietary mercury exposure causes oxidative stress, brain lesions, and altered behaviour in Atlantic salmon (Salmo salar) parr. Aquat. Toxicol., 65: 55-72. DOI: 10.1016/S0166-445X(03)00104-8

[55] Mieiro, C.L., Ahmad, I., Pereira, M.E., Duarte, A.C., Pacheco, M. (2010). Antioxidant system breakdown in brain of feral golden grey mullet (Liza aurata) as an effect of mercury exposure. Ecotoxicology , 19 (6): 1034-1045. DOI:10.1007/s10646-010-04850

[56] Monteiro, D.A., Rantin, F.T., Kalinin, A.L. (2010). Inorganic mercury exposure: toxicological effects, oxidative stress biomarkers and bioaccumulation in the tropical freshwater fish matrinxã, Brycon amazonicus (Spix and Agassiz, 1829). Ecotoxicology, 19 (1): 105-123. DOI:10.1007/s10646-009-0395-1

[57] Valko, M., Morris, H., Cronin, M.T. (2005). Metals, toxicity and oxidative stress. Curr. Med. Chem., 12: 1161-1208.

[58] Schlenk, D., Wolford, L., Chelius, M., Steevens, J., Chan, K.M. (1997). Effect of arsenite, arsenate, and the herbicide monosodium methyl arsonate (MSMA) on hepatic metallothionein expression and lipid peroxidation in channel catfish. Comp. Biochem. Physiol., C 118: 177-183. DOI: 10.1016/S0742-8413(97)00083-2

[59] Stara, A., Kristan, J., Zuskova, E., Velisek, J. (2013). Effect of chronic exposure to prometryne on oxidative stress and antioxidant response in common carp (Cyprinus carpio L.). Pestic. Biochem. Physiol., 105: 18-23. DOI: 10.1016/j.pestbp.2012.11.002 
[60] Pe $\sim$ na-Llopis, S., Ferrando, M.D., Pe na, J.B. (2003). Increased recovery of brain acetylcholinesterase activity in dichlorvos-intoxicated European eels Anguilla anguilla by bath treatment with N-acetylcysteine. Dis. Aquat. Organ., 55: 237-245.

[61] Thomaz, J.M., Martins, N.D., Monteiro, D.A., Rantin, F.T., Kalinin, A.L. (2009). Cardiorespiratory function and oxidative stress biomarkers in Nile tilapia exposed to the organophosphate insecticide trichlorfon (NEGUVON). Ecotoxicol. Environ. Saf., 72: 1413-1424. DOI: 10.1016/j.ecoenv.2008.11.003

[62] Monteiro, D.A., Rantin, F.T., Kalinin, A.L. (2009). The effects of selenium on oxidative stress biomarkers in the freshwater characid fish matrinxa, Brycon cephalus (Günther, 1869) exposed to organophosphate insecticide Folisuper 600 BR (methyl parathion). Comp. Biochem. Physiol., C 149: 40-49. DOI: 10.1016/j.cbpc.2008.06.012.

[63] Piner, P., Sevgiler, Y., Uner, N. (2007). In vivo effects of fenthion on oxidative processes by the modulation of glutathione metabolism in the brain of Oreochromis niloticus. Environ. Toxicol., 22: 605-612.

[64] Rosety, M., Rosety-Rodríguez, M., Ordonez, F.J., Rosety, I. (2005). Time course variations of antioxidant enzyme activities and histopathology of gilthead seabream gills exposed to malathion. Histol. Histopathol., 20: 1017-1020.

[65] Ruiz-Leal, M., George, S. (2004). An in vitro procedure for evaluation of early stage oxidative stress in an established fish cell line applied to investigation of PHAH and pesticide toxicity. Mar. Environ. Res., 58: 631-635. DOI: 10.1016/j.marenvres.2004.03.054

[66] Filipak Neto, F., Zanata, S.M., Silva de Assis, H.C., Nakao, L.S., Randi, M.A., Oliveira Ribeiro, C.A. (2008). Toxic effects of DDT and methyl mercury on the hepatocytes from Hoplias malabaricus. Toxicol. In Vitro, 22: 1705- 1713. DOI: 10.1016/j.tiv.2008.07.006

[67] Doğan, N., Yazıcı, Z., Şişman, T. (2011). Lepistes balığının karaciğeri üzerine fenpiroksimat akarisitinin biyokimyasal etkileri. BAÜ Fen Bil. Enst. Dergisi, 13(1): 1-8.

[68] Parvez, S., Raisuddin, S. (2006). Effects of paraquat on the freshwater fish Channa punctata (Bloch): non- enzymatic antioxidants as biomarkers of exposure. Arch. Environ. Contam. Toxicol., 50: 392-397. DOI: 10.1007/s00244-005-5083-4

[69] Bretaud, S., Lee, S., Guo, S. (2004). Sensitivity of zebrafish to environmental toxins implicated in Parkinson's disease. Neurotoxicol. Teratol., 26: 857-864. DOI:10.1016/j.ntt.2004.06.014

[70] Stephensen, E., Sturve, J., Förlin, L. (2002). Effects of redox cycling compounds on glutathione content and activity of glutathione-related enzymes in rainbow trout liver. Comp. Biochem. Physiol., C 133: 435-442. DOI: 10.1016/S1532-0456(02)00129-1

[71] Wright, J., George, S., Martinez-Lara, E., Carpene, E., Kindt, M. (2000). Levels of cellular glutathione and metallothionein affect the toxicity of oxidative stressors in an established carp cell line. Mar. Environ. Res., 50: 503-508. DOI: 10.1016/S01411136(00)00125-2

[72] Hook, S.E., Skillman, A.D., Small, J.A., Schultz, I.R. (2006). Gene expression patterns in rainbow trout. Oncorhynchus mykiss, exposed to a suite of model toxicants. Aquat. Toxicol., 77: 372-785. DOI: 10.1016/j.aquatox.2006.01.007

[73] Hai, D.Q., Varga, S.I., Matkovics, B. (1997a). Effects of diethyl-dithiocarbamate on antioxidant system in carp tissue. Acta Biol. Hung., 48: 1-8.

[74] Lushchak, V.I. (2007). Free radical oxidation of proteins and its relationship with functional state of organisms. Biochemistry (Moscow), 72: 809-827.

[75] Pena-Llopis, S., Pena, J.B., Sancho, E., Fernandez-Vega, C., Ferrando, M.D. (2001). Glutathione-dependent resistance of the European eel Anguilla anguilla to the herbicide molinate. Chemosphere, 45: 671-681. DOI: 10.1016/S0045-6535(00)00500-2 
[76] Dorval, J., Hontela, A. (2003). Role of glutathione redox cycle and catalase in defense against oxidative stress induced by endosulfan in adrenocortical cells of rainbow trout (Oncorhynchus mykiss). Toxicol. Appl. Pharmacol., 192: 191-200. DOI: 10.1016/S0041-008X(03)00281-3

[77] Bagnyukova, T.V., Storey, K.B., Lushchak, V.I. (2005a). Adaptive response of antioxidant enzymes to catalase inhibition by aminotriazole in goldfish liver and kidney. Comp. Biochem. Physiol. B. Biochem. Mol. Biol., 142: 335-341. DOI:10.1016/j.cbpb.2005.08.003

[78] Bagnyukova, T.V., Vasylkiv, O.Y., Storey, K.B., Lushchak, V.I. (2005b). Catalase inhibition by amino triazole induces oxidative stress in goldfish brain. Brain Res., 1052: 180-186. DOI:10.1016/j.brainres.2005.06.002

[79] Lushchak, O.V., Kubrak, O.I., Torous, I.M., Nazarchuk, T.Y., Storey, K.B., Lushchak, V.I., 2009c. Trivalent chromium induces oxidative stress in goldfish brain. Chemosphere, 75: 56-62. DOI: 10.1016/j.chemosphere.2008.11.052

[80] Glusczak, L., dos Santos Miron, D., Crestani, M., Braga da Fonseca, M., de Araujo Pedron, F., Duarte, M.F., Vieira, V.L. (2006). Effect of glyphosate herbicide on acetylcholinesterase activity and metabolic and hematological parameters in piava (Leporinus obtusidens). Ecotoxicol. Environ. Saf., 65: 237-241. DOI: 10.1016/j.ecoenv.2005.07.017

[81] Glusczak, L., dos Santos Miron, D., Moraes, B.S., Simxes, R.R., Schetinger, M.R., Morsch, V.M., Loro, V.L. (2007). Acute effects of glyphosate herbicide on metabolic and enzymatic parameters of silver catfish (Rhamdia quelen). Comp. Biochem. Physiol., C 146: 519-524. DOI:10.1016/j.cbpc.2007.06.004

[82] Şişman T., Geyikoğlu F. (2010). PCB 126'ya maruz kalmış Zebra balığg1 (Danio rerio) larvalarındaki sensorimotor hasarlar. TUBAV Bilim Dergisi, 3(1): 61-66.

[83] Song, S.B., Xu, Y., Zhou, B.S. (2006). Effects of hexachlorobenzene on antioxidant status of liver and brain of common carp (Cyprinus carpio). Chemosphere, 65: 699706. DOI:10.1016/j.chemosphere.2006.01.033

[84] Sanchez, W., Piccini, B., Porcher, J.M. (2008). Effect of prochloraz fungicide on biotransformation enzymes and oxidative stress parameters in three-spined stickleback (Gasterosteus aculeatus L.). J. Environ. Sci. Health, Part B 43: 65-70. DOI : 10.1080/03601230701735151

[85] Winston, G.W., Di Giulio, R.T. (1991). Prooxidant and antioxidant mechanisms in aquatic organisms. Aquat. Toxicol., 19: 137-161. DOI: 10.1016/0166-445X(91)90033-6

[86] Livingstone, D.R. (2001). Contaminant-stimulated reactive oxygen species production and oxidative damage in aquatic organisms. Mar. Pollut. Bull., 42: 656- 666. DOI:10.1016/S0025-326X(01)00060-1

[87] Sturve, J., Hasselberg, L., Fälth, H., Celander, M., Förlin, L. (2006). Effects of North Sea oil and alkylphenols on biomarker responses in juvenile Atlantic cod (Gadus morhua). Aquat. Toxicol., 78: 73-78. DOI:10.1016/j.aquatox.2006.02.019

[88] Ameur, W.B., de Lapunte, J., El Megdiche, Y., Barhoumi, B., Trabelsi, S., Camps, L., Serret, J., Ramos-Lopez, D., Gonzalez-Linares, J., Driss, M.R., Borras, M. (2012). Oxidative stress, genotoxicity and histopathology biomarker responses in mullet (Mugil cephalus) and sea bass (Dicentrarchus labrax) liver from Bizerte Lagoon (Tunisia). Mar. Pollut. Bull., 64: 241-251. DOI: 10.1016/j.marpolbul.2011.11.026

[89] Gauthier, P.T., Norwood, W.P., Prepas, E.E., Pyle, G.G. (2014). Metal-PAH mixtures in the aquatic environment: A review of co-toxic mechanisms leading to more-thanadditive outcomes. Aquat. Toxicol., 154: 253-269. DOI: 10.1016/j.aquatox.2014.05.026 
[90] Hasselberg, L., Meier, S., Svardal, A. (2004a). Effects of alkylphenols on redox status in first spawning Atlantic cod (Gadus morhua). Aquat. Toxicol., 69: 95-105. DOI: 10.1016/j.aquatox.2004.04.004

[91] Hasselberg, L., Meier, S., Svardal, A., Hegelund, T., Celander, M.C. (2004b). Effects of alkylphenols on CYP1A and CYP3A expression in first spawning Atlantic cod (Gadus morhua). Aquat. Toxicol., 67: 303-313. DOI:10.1016/j.aquatox.2003.12.007

[92] Uguz, C., Iscan, M., Erguven, A., Isgor, B., Togan, I. (2003). The bioaccumulation of nonyphenol and its adverse effect on the liver of rainbow trout (Onchorynchus mykiss). Environ. Res., 92: 262-270.

[93] Hughes, E.M., Gallagher, E.P. (2004). Effects of 17-[beta] estradiol and 4- nonylphenol on phase II electrophilic detoxification pathways in largemouth bass (Micropterus salmoides) liver. Comp. Biochem. Physiol., C 137: 237-247. DOI: 10.1016/j.cca.2004.01.006

[94] Akbulut C., Kızıl Ç., Yön N. D. (2013). Effects of Low Doses of Bisphenol A on Primordial Germ Cells in Zebrafish (Danio rerio) Embryos and Larvae. Kafkas Univ Vet Fak Derg., 19(4): 647-653. DOI: 10.9775/kvfd.2013.8600 